\title{
EL DESCARTES DE SPINOZA
}

\author{
Daniel Moreno Moreno \\ IES Miguel Servet (Zaragoza) \\ dmoreno@unizar.es
}

\section{RESUMEN}

A Spinoza le interesa sobre todo el Descartes metafísico y teológico. Ese es el Descartes que aparece en los Principios de filosofía cartesiana, que Spinoza publicó en 1663. El artículo analiza con detenimiento ese texto: Principios de la filosofía cartesiana. El planteamiento de Descartes queda expuesto con suma lógica y, a la vez, aparece el distinto talante de Spinoza, que ahí se muestra ya entre líneas. A partir de ese análisis, se concluye que Spinoza fue un cartesiano sui generis y un teólogo alejado de la visión tradicional de Dios, pero no por ello ateo en sentido estricto.

Palabras Clave: esencia, existencia, necesidad, infinito, Dios, escolástica, teología.

\section{SPINOZA'S DESCARTES}

\section{Abstract}

Spinoza was interested mainly in Descartes' theology and metaphysics. So, when he was exploring Descartes' Principles of Philosophy, he focused on these topics. This paper analyzes Spinoza's Principles of Cartesian Philosophy (1663). Spinoza exposed Cartesian claims in a very logical way, and, at the same time, Spinozian mood can well be seen between the lines. This analysis concludes that Spinoza was a sui generis Cartesian, and a theologian who defended a not very traditional vision of Good, but not an atheist one, strictly understood. Keywords: essence, existence, necessity, infinite, Good, Scholastic, Theology.

DOI: http://doi.org/10.25145/j.laguna.2018.42.002 
Una vez publicados, en esta misma revista, mis estudios «Antropología cartesiana» [Laguna, n. ${ }^{\circ}$ 38, 2016, pp. 19-36] y "Gnoseología cartesiana» [Laguna, n. ${ }^{\circ}$ 40, 2017, pp. 51-68], estaba preparado el terreno para abordar la teología cartesiana. Sin embargo, la tarea no resultaba nada sencilla, dada su proverbial prudencia, lo, a veces, escurrido de sus planteamientos teológicos y las múltiples réplicas y contrarréplicas que este asunto motivó en las sucesivas objeciones y respuestas a sus Meditaciones de filosofía primera. Es por eso por lo que decidí abordar el trabajo de un alumno aventajado que ya había hecho esa labor en su momento: Spinoza, entonces un cartesiano residente en Ámsterdam, que había sido expulsado de la comunidad judía y que pronto adquiriría fama de ateo, y que mantenía numerosos contactos intelectuales en un lugar que reunía precisamente lo más granado de Europa. El lector encontrará así un detallado análisis del primer libro publicado por Spinoza, que permitirá presentar la teología de Descartes, el nuevo acento que le imprime el original intérprete y, a modo de conclusión, me permitirá responder si y en qué sentido Spinoza era cartesiano y en qué medida su particular acercamiento a Dios justifica ser llamado ateo.

\section{SPINOZA SEGUIDOR DE DESCARTES}

Según informa Luis Meyer, amigo de Spinoza y cartesiano él mismo, en su presentación del primer escrito publicado por Benito de Spinoza, de Ámsterdam, Renati des Cartes principiorum philosophiae Pars I et II, more geometrico demonstratae ${ }^{1}$ (1663) -libro que incluía el Apéndice Cogitata metaphysica-, Spinoza era uno de los que consideraban a Descartes el astro "más brillante de nuestro siglo»; de ahí que hubiera preparado una exposición de los Principia philosophiae ${ }^{3}$ cartesianos, al modo geométrico, inspirado en los Elementos de Euclides y en el ejemplo del propio Descartes, quien, a petición de los autores de las Segundas Objeciones, había incluido "more geometrico dispositae»" ${ }^{4}$ al final de sus Respuestas, las ideas de sus

${ }^{1}$ Este es el título de la cubierta; en las páginas interiores el título que aparece es Principia philosophiae cartesianae; de ahí procede el título abreviado Principios de la filosofía cartesiana y la abreviatura con que es conocida: PPC.

2 Spinoza, B.: Principios de filosofía de Descartes y Pensamientos metafísicos, recogido en Tratado de la reforma del entendimiento/Principios de filosofía de Descartes/Pensamientos metafísicos. Edición de Atilano Domínguez. Madrid, Alianza Editorial, 1988, p. 128. Cotejado con Spinoza Opera (Carl Gebhardt, ed.), vol. I, pp. 123-281. Disponible en http://spinoza.tk/ppccm.pdf. Abreviado en adelante como PPC.

${ }^{3}$ Ha de recordarse que Spinoza leyó los Principia y las Meditationes cartesianas en su versión original, esto es, en latín; las traducciones españolas disponibles de ambas obras, sin embargo, están hechas a partir de las traducciones al francés hechas ya en vida de Descartes; las diferencias entre las versiones latina y francesa no son muchas, pero acaban siendo relevantes.

${ }^{4}$ Como es sabido, Descartes necesitó para ello nueve Definiciones, siete Postulados, diez Axiomas, cuatro Proposiciones y un Corolario. Cf. Descartes, R.: Meditaciones metafísicas. Edición de Vidal Peña. Oviedo, Krk, 2005, pp. 160-170. Cotejado con la versión latina en Ouvres de Des- 
Meditationes de prima philosophia sobre Dios y sobre la distinción entre la mente y el cuerpo humanos. Como presentación de Spinoza, Meyer dice que es «un experto tanto en el método analítico como en el sintético, y familiarizado sobre todo con los escritos de Descartes y profundo conocedor de su filosofía» (PPC 129). De ahí que le animara a exponer la filosofía de Descartes al modo sintético; empuje y aceptación, todo hay que decirlo, poco cartesianas porque Descartes había desaconsejado la exposición sintética de las cuestiones metafísicas. La diferencia entre ambos métodos de exposición es que el análisis parte de los efectos, es decir, de lo que todo el mundo sabe y tal como lo sabe y, desde ahí, pregunta por lo que hay antes, su dirección es a priori, hacia atrás, hacia la causa y hacia lo más evidente, hacia cómo son las cosas de verdad; por eso es fácil de seguir y más pedagógico, aunque, apunta Descartes, algunas cosas son tan obvias que se dejan de explicitar y luego pueden dar lugar a malentendidos. El método sintético, por el contrario, parte de las causas, de lo más evidente, expuesto al modo de axiomas, y de ahí se dirige a posteriori, hacia abajo, hacia los efectos, paso a paso y sin dejar nada por fundamentar en lo anterior, avanza al paso de proposiciones y corolarios -con algún escolio, que suple lo que no queda claramente dicho en proposiciones y corolarios-; el problema de este método es que los axiomas geométricos se aceptan por su evidencia mientras que los axiomas metafísicos son fácilmente discutibles en una primera lectura, aunque, una vez aceptados, se puede volver a ellos cada vez que alguna nueva proposición genere reticencias5.

\section{EXPOSICIÓN DE PARTE DE LOS PRINCIPIA PHILOSOHIAE DE RENATO DESCARTES}

Meyer informa además que Spinoza elaboró en primer lugar la Parte Segunda, que corresponde a la Segunda Parte de los Principios de filosofía cartesianos. Y efectivamente, ahí expone Spinoza la naturaleza de la materia, la naturaleza del movimiento, las leyes del movimiento y las reglas del choque. La Tercera Parte aparece sólo comenzada y faltaría la Cuarta Parte, que habría de corresponder a la cuarta de los Principia.

Como en toda exposición, por fiel que sea, se aprecian ligeros desacuerdos de Spinoza con Descartes, de los que él mismo avisa y que Meyer ya anuncia desde su "Saludo al benévolo lector», seguramente porque conocía el manuscrito donde Spinoza apuntaba un ambicioso sistema filosófico y que nosotros ahora conocemos en su traducción holandesa, me refiero al conocido como Tratado breve sobre Dios,

cartes, vol. VII. Meditationes de prima philosophia. Edición de Charles Adam y Paul Tannery. París, 1904. Consultado en archive.org y, para las páginas que faltan, en fr.wikisource.org. Abreviado en adelante como $\mathrm{M}$.

${ }^{5}$ Cf. M 155-159. Como se irá viendo, Spinoza sigue el método sintético en la Parte II de su libro, en la Parte I comienza con una exposición analítica y sigue con una exposición sintética; y sus Cogitata presentan un orden sintético en la sucesión de capítulos, pero sin axiomas ni proposiciones. 
el ser humano y la felicidad ${ }^{6}$. Uno de los desacuerdos mostrados en la exposición de esa Segunda Parte quizá sea que en el Escolio de la Proposición 6 se lee que «la división y el movimiento son concebidos por nosotros de infinitos modos; de ahí que también podamos concebir infinitas variaciones de la materia» (PPC 192), cuando el mismo Spinoza acaba de recordar en el Escolio de la Proposición 5 que, para Descartes, «el infinito y sus propiedades superan el entendimiento humano, que es finito por naturaleza» (PPC 190) y sabemos que Descartes prefiere hablar de indefinido para referirse, por ejemplo, al número de estrellas o a los números pares o impares y que en el art. 27 de sus Principia I aclara que reserva el término infinito exclusivamente para Dios? ${ }^{7}$. Aunque, en conjunto, la física cartesiana le resulta a Spinoza convincente: a la extensión no le pertenecen las cualidades sensibles pero sí el movimiento ${ }^{8}$ y la divisibilidad, por lo que hay partículas pero no átomos ni vacío.

La Primera Parte fue compuesta, al parecer ${ }^{9}$, de modo apresurado, para publicar el libro. Cabe pensar, entonces, que, dado que se le añadió Apéndice con Pensamientos metafísicos, la parte teológico-antropológico-metafísica era más importante que la parte físico-cosmológica, que quedó inconclusa. Clara muestra, a mi entender, de que los talantes de Spinoza y de Descartes eran bastante distintos.

Resulta, además, que las ideas de la Primera Parte de los Principia cartesianos quedan expuestas por partida doble: de modo razonado, tal como se van descubriendo -analítico o a priori, en la terminología cartesiana-, en la Introducción y ordenadas al modo geométrico, tal como unas se siguen de otras -sintético o a posteriori-, en el resto de la Parte I. En ambas, se muestra Spinoza como un lector muy atento a los matices cartesianos, aunque no puede evitar mostrar su propio talante. Digo que su lectura es muy fina porque, al exponer el proceso de la duda que lleva al «ego sum cogitans» (PPC 144), aclara que cogito ergo sum no es un silogismo y que el pensamiento incluye todos sus modos, desde dudar, querer o sentir; distingue, además, entre anima en tanto que «algo exiguo, a modo de viento, de fuego o de éter; difuso entre las partes más densas de su cuerpo» (idem.), que pertenecería, tal como Descartes estableció, a la res extensa, y mens, que es el término que Descartes prefirió a anima -cambio que ya distinguía a los cartesianos como grupo nuevo

${ }^{6}$ Spinoza, B.: Tratado breve. Edición de Atilano Domínguez. Madrid, Alianza Editorial, 1990.

7 Cf. Descartes, R.: Los principios de la filosofía. Edición de Guillermo Quintás. Madrid, Alianza Editorial, 1995. Versión latina en Ouvres de Descartes, vol. VIII. Principia philosophiae (Premiére partie). Edición de Charles Adam y Paul Tannery, París, 1905. Disponible en https://archive.org/.

${ }^{8}$ Es interesante por demás su defensa ante los argumentos de Zenón contra del movimiento local ( $c f$. PPC, Proposición 6, Escolio).

${ }_{9}$ Así lo recoge Meyer en su prólogo ( $c f$. PPC 131), y Atilano Domínguez, en su edición de $\mathrm{PPC}$, recuerda que el propio Spinoza insistió en que la compuso «en dos semanas» (cf. Introducción general a PPC, p. 41). 
con terminología característica ${ }^{10}-$, y que es el que Spinoza utiliza desde esta primera Introducción y que mantiene a lo largo de toda su obra ${ }^{11}$.

La discrepancia asoma cuando Spinoza expone la crítica más directa al planteamiento cartesiano, la respuesta de Descartes y, dado que «esta respuesta no satisface a algunos» (PPC 147), cuando da -o, más bien, apunta- la propia. La crítica era: dado que la existencia de Dios no es evidente por sí misma, nada será cierto, ni siquiera que Dios exista. La respuesta de Descartes había sido que lo más cierto es el propio pensamiento, que de ahí se sigue la existencia de un Dios no engañador, aunque es posible que los pasos de esa demostración se olviden y pueda surgir la duda, que esta desaparecerá cuando se vuelva a recorrer el camino demostrativo. Spinoza parece encontrarse entre quienes no quedan conformes con esa respuesta, detectando seguramente que, de ese modo, Dios, que es el origen, posee menos certeza que el pensamiento, que es su efecto. De ahí que en su respuesta alternativa señale un objetivo más ambicioso: el mismo tipo y grado de evidencia que posee el pensamiento -que es máxima, hasta el punto de ni siquiera fingir que Dios nos engaña ${ }^{12}$ la hace conmoverse- es el tipo y grado de evidencia que ha de tener la idea de Dios, no exactamente la existencia de Dios, dado que ese tipo de evidencia máximo versa sobre ideas, no sobre existencias que puedan ser objeto de duda. La clave es, por tanto, tener «una idea verdadera de Dios» (idem.), de modo que, una vez alcanzada, ya no se pueda dudar de que los ángulos de un triángulo sumen dos rectos. Para más adelante deja Spinoza mostrar su argumento completo: la idea de Dios, y sólo esa idea, lleva consigo que Dios existe necesariamente. Pero el cambio de enfoque es claro. A Spinoza le gusta empezar por el origen, por Dios mismo: la certeza máxima de la idea de Dios - de tal grado que ni la posibilidad de que Dios sea engañador la hará dudosa, y que ese grado se dé lo muestra Descartes en el «soy

${ }^{10}$ En sus Observaciones sobre un programa impreso en Bélgica, firmadas en Egmont en diciembre de 1647, reconoce Descartes que usar la expresión mente humana en lugar de alma racional era algo ya característico del cartesianismo ( $C f$. DesCARTEs, R.: Observaciones sobre un programa impreso hacia el fin del año 1647, bajo el siguiente titulo: Explicación de la mente humana o del alma racional, que incluye la exposición de lo que es y de lo que puede ser. Edición de Guillermo Quintás. Valencia, Cuadernos Teorema, 1981. Cotejado con Ouvres de Descartes, vol. VIII. Principia philosophiae (Seconde partie). Edición de Charles Adam y Paul Tannery, París, 1905, p. 347. Consultado en https://archive.org/.

${ }^{11}$ Llama por ello la atención que este matiz se le escape a Atilano Domínguez. De modo que, cuando Spinoza mismo, en la aclaración a la Definición 6, explica: «Y hablo aquí de mente más bien que de alma porque el término alma es equívoco y se toma con frecuencia por una cosa corporal» (PPC 150), Atilano, en su erudita nota, concluye, de modo bastante sorprendente: «Y así, mens lo hemos traducido por mente, si indica el alma como principio de conocimiento, y por alma, si indica una realidad contrapuesta al cuerpo" (Cf. sus Notas a PPC, p. 318). Cuando lo lógico sería no aplicar a Spinoza una distinción que le es ajena y respectar la que él acepta de Descartes: anima nombra el concepto tradicional de alma, de claras connotaciones corporalistas en tanto que principio de vida -incluso, a veces, identificado con la sangre-, y mens nombra todas las actividades mentales en tanto que mentales, en tanto que nos damos cuenta de ellas.

${ }_{12}$ Que Dios pueda ser engañador es una posibilidad que incomoda de modo extremo a Spinoza, mientras que para Descartes era meramente un experimento mental. 
pensante»- dotará de certeza a todas las ideas adecuadas, del mismo modo que la existencia de Dios dotará de realidad al Pensamiento y a la Extensión.

La parte expuesta geométricamente, esto es, según el orden sintético a posteriori, sigue muy de cerca la exposición cartesiana recogida al final de sus Respuestas a las Segundas Objeciones a sus Meditaciones. El cambio principal que hace Spinoza es intercalar tres axiomas y cuatro proposiciones para mostrar la evidencia de la mens o res cogitans -o cogito o sum cogitans-, "único y certísimo fundamento de toda la filosofía» (PPC 153). Aunque el cambio de acento es claro en estas afirmaciones: 1) que la idea que contiene objetivamente el ser y la perfección de la sustancia es mucho más perfecta que la que contiene la perfección de algún accidente y 2) que la más perfecta de todas es la idea del ser sumamente perfecto; «estas ideas no sólo las percibimos con la misma evidencia y claridad, sino también, quizá, con mayor distinción que nuestro principio. Ya que no sólo afirman que pensamos, sino también cómo pensamos» (PPC 154). Para Spinoza ambas ideas tienen la misma evidencia que la imposibilidad de afirmar que ex nihilo aliquid fiat ${ }^{13}$. Que este matiz es muy importante para Spinoza se muestra en la extensa explicación a su Axioma 9, que corresponde al Axioma 5 de Descartes: la realidad objetiva de nuestras ideas requiere una causa en la que se contenga la misma realidad, no sólo objetivamente, sino o formalmente o eminentemente. Por este Axioma se muestra que las ideas son ideas de algo, de un objeto, es decir, que refieren a algo que no son ellas mismas; en tanto que ideas todas son iguales, pero en función del objeto al que representen hay grandes diferencias: la idea de algo más perfecto tendrá como causa algo más perfecto ${ }^{14}$. Así, adelanta Spinoza: «Si alguien tuviera una idea que contuviera más realidad objetiva que realidad formal contuviera él mismo, necesariamente buscaríamos, guiados por la luz natural, otra causa que contuviera toda esa perfección o formal o eminentemente fuera de él mismo» (PPC 156).

De este modo, queda despejado el camino a las proposiciones que muestran que: 1) la existencia de Dios se conoce simplemente considerando su naturaleza;

${ }_{13}$ Merece la pena detenerse en este paso porque el mismo Descartes incluyó entre las Nociones comunes o axiomas, junto a otros principios lógicos, el principio de su filosofía, formulado así: Is qui cogitat, non posest non existere dum cogitat (cf. Principia I, art. 49). Lo que hace Spinoza es seguir a su maestro e incluir entre los principios lógicos las dos ideas que soportarán el papel que le asigna a Dios en su sistema.

${ }^{14}$ Cf. Principia I, art. 17, al que remite Spinoza. Descartes pone el ejemplo de alguien que tenga la idea de una máquina muy compleja: se habrá de pensar que, o bien la ha visto en otro lugar o bien es tan aventajado en el arte mecánico que él mismo la ha inventado. Spinoza no debió quedar muy convencido porque propone otros dos ejemplos: 1) si se ven varios libros y se los considera sólo como tales, se puede pensar que son iguales, pero, si se los lee y se comprueba que uno es de un insigne filósofo y otro de un charlatán, se concluirá que la causa del primero es más perfecta que la del segundo; 2) si se contempla la efigie de un príncipe y se la compara con otra de los mismos materiales, no habrá diferencia, esta surge cuando se pregunta a quién representa cada cual, porque hay que buscar la causa donde esa figura esté o formal o eminentemente: el príncipe. Como este axioma conduce a la demostración de Dios, se ve que Spinoza es más cuidadoso que Descartes al colocar a Dios fuera de la mente, nunca como posible mera invención. 
2) que se demuestra por el solo hecho de que su idea esté en nosotros $\left.{ }^{15} ; 3\right)$ también porque nosotros, que tenemos la idea de Dios, existimos; 4) que toda la perfección de Dios procede de Él mismo; 5) que no hay varios dioses; 6) que la fuerza de Dios conserva todo lo que existe; 7) que Dios es incorpóreo; 8) inmutable; 9) eterno; 10) que todo lo preordenó Dios desde la eternidad. Como se ve, toda una teodicea, presente desde luego en Descartes, pero que Spinoza selecciona y destaca, acudiendo ya a los Principia ya a las Meditationes. De modo que, siendo cierto que en esta primera parte habla también del error ${ }^{16}$, de la libertad como determinación en vez de como indiferencia y de la unión de mente y cuerpo, cualquier lector de Principia I y de esta Parte I dedicada a esos Principia I notaría ostensibles diferencias de contenido, de importancia relativa de las cuestiones y de matices. Es más, Spinoza señala varias veces hacia su Apéndice Pensamientos metafísicos, dedicados al ser y a Dios. Y creo ver en pasajes como este el talante propio de Spinoza:

Que la existencia necesaria pertenece a la naturaleza de Dios o que el concepto de Dios implica la existencia necesaria (como el concepto de triángulo implica que sus tres ángulos son iguales a dos rectos) o que sea una verdad eterna que su existencia no sea distinta de su esencia: de todo esto depende el conocimiento de los atributos de Dios, por el que somos conducidos a su amor o suprema felicidad. Por eso sería muy de desear que el género humano llegara a aceptar, de una vez, estas cosas con nosotros (PPC 158-9).

Así la beatitudo es el objetivo de Spinoza, un objetivo muy humano y que él vincula a Dios. Destaca también el comentario recogido en el Escolio a la Proposición 6, donde se muestran in nuce los amplios desacuerdos futuros con los predicadores:

Hay algunos que niegan tener idea alguna de Dios y que, sin embargo, como dicen, lo veneran y aman. Y, por mucho que se les ponga ante los ojos la definición de Dios y los atributos de Dios, con todo, nada se avanza; ni más ni menos que si uno se empeñara en enseñar a un ciego de nacimiento las diferencias de los colores, tal

15 Cf. PPC 160-167. Esta es la famosa Proposición 7, recogida por Descartes en Principia $I$, art. 21 y en Meditationes ( $c f$. M 48-52 y 168-7). A Spinoza le parece correcta pero mal demostrada porque, en la formulación cartesiana, se contempla la posibilidad de que cada cual se conserve a sí mismo y, por tanto, pueda darse todas las perfecciones, posibilidad que horroriza a Spinoza porque eso es algo que sólo Dios puede hacer; además, Descartes parece distinguir realmente entre sustancia y atributo, algo imposible; además, porque no demuestra a Dios como necesario y perfectísimo desde sí mismo sino desde la idea que nos hacemos de las perfecciones que nos faltan. En definitiva, Descartes parece conceder demasiada relevancia a la mente humana en esta demostración, mientras que en la demostración spinoziana todo el peso cae sobre Dios como necesario y perfecto. Spinoza muestra, también, que su concepción metafísica bebe la tradición platónica, en tanto que su argumentación se basa en los grados del ser, desde la pura nada al puro ser.

16 Respecto al error, la postura defendida por Spinoza es la de Descartes, en función del distinto radio de la voluntad y el entendimiento, y en base al libre albedrío (Principia I, art. 35, 37), pero el contexto de la demostración es propio de Spinoza: que el error no es algo positivo, porque, en ese caso, tendría a Dios como causa. Como advierte Meyer en PPC 132, Spinoza no distingue entre voluntad y entendimiento ni defiende el libre albedrío, que son las bases del planteamiento cartesiano. 
como nosotros las vemos. A decir verdad, a menos que queramos tenerlos por un nuevo género de animales, intermedio entre los hombres y los brutos, poco debemos preocuparnos de sus palabras. [...] no tenemos por qué perder el tiempo con las palabras de quienes niegan la idea de Dios, simplemente porque son incapaces de formar ninguna imagen suya en su cerebro ${ }^{17}$ (PPC 160).

\section{LAS COGITATA METAPHYSICA O SPINOZA ENTRE DESCARTES Y LA RENOVADA ESCOLÁSTICA}

Nada de extraño tiene que los Pensamientos metafísicos-«donde se explican brevemente las cuestiones más difíciles que se presentan tanto en la parte general como en la especial, de la metafísica respecto al ser y sus afecciones, a Dios y sus atributos, y a la mente humana»- traten del ser y de Dios. La distinción principal con la que se abren es la distinción entre ser necesario y ser contingente, que procede de la teología musulmana y judía, de donde pasó a la vía de la contingencia tomista, presente en Descartes y que Spinoza pasa a primer plano. Descartes la recoge como Postulado 5 y como Axioma 10 en sus Respuestas a las Segundas Objeciones, y Spinoza las había formulado así en su Axioma 6, que era axial en sus demostraciones: en la idea o concepto de cualquier cosa se contiene la existencia, ya posible ya necesaria (véase el Axioma 10 de Descartes): necesaria en Dios, o concepto del ser sumamente perfecto, ya que, de lo contrario, se lo concebiría imperfecto, en contra de lo que se supone; contingente, en cambio, o posible en el concepto de una cosa limitada ( $c f$. PPC 155). De modo que Spinoza tiene a Descartes como guía en este su adentramiento en la metafísica y teología escolásticas, y a él remite en varias ocasiones $^{18}$. El propio título Cogitata remite al cogito cartesiano, e inaugura un nuevo tipo de texto filosófico - que procede de modo sintético a base de capítulos, no de axiomas y proposiciones-, que añadir a los Essais, a las Disputationes, a las Quaestiones o a las Meditationes.

El capítulo r entiende el ser-ens-como aquello que existe, ya necesariamente ya, al menos, como que puede existir. Spinoza descarta, entonces, cosas que parecen seres pero que no lo son: un cuadro redondo ni siquiera puede existir-Chimaera-, si existiera un centauro sería sólo por casualidad porque es una combinación azarosa de elementos -Ens fictum-; más atención necesita el Ens rationis. Spinoza quiere desmarcarse de la división escolástica del ser en ser real y ser de razón porque el ser de razón no es ser, por tanto no puede incluirse como división del ser. El ser de razón incluye palabras, divisiones y conceptos que usamos para recordar, entender e imaginar las cosas reales, pero ellos mismos no son reales; si se olvida ese detalle, habrá que pensar que los entes de razón tienen referentes en el mundo extenso, nota 6 supra.

${ }^{17}$ Creo que esta referencia coincide con los teólogos referidos en Tratado breve, cap. 7. Cf.

${ }_{18}$ Para la explicación de los modos de pensar como entes de razón, por ejemplo, Spinoza sigue de cerca los Principia I, arts. 51-62. 
algo imposible. Por eso Spinoza matiza que los entes de ficción, por casualidad, sí podrían encontrar un referente exterior, algo imposible para palabras como género, especie, tiempo, número, etc. En un sentido, los entes de razón son por tanto pura nada, dado que son ideas sin contenido objetivo real, pero, por otro, son entes reales, en tanto que son modos de pensar que realmente se dan en la persona que los está pensando, pero, en ese caso, el ente real es la persona. También matiza Spinoza que el ser se divide en sustancia y modo, no en sustancia y accidente; en efecto, según el mismo Descartes establece en Principia I, arts. 51-52 y 56, la sustancia como tal nunca existe, siempre ha de existir con sus atributos, como la existencia o la duración, luego esta distinción es sólo de razón, nunca estará realmente la sustancia separada de sus atributos; sin embargo, la sustancia más atributos sí que puede existir de modo necesario o posible, luego el ser se divide efectivamente en sustancia -se entiende, inseparable de sus atributos- y modo, en tanto que son modificaciones comprobables del ser. Una vez aclarados estos matices, el ser queda dividido en «ser que existe necesariamente por su naturaleza, o cuya esencia implica la existencia, y ser cuya esencia no implica la existencia, a no ser como posible» (PPC 236).

De ahí que el capítulo II se dedique a la distinción entre esencia y existencia. Como tal distinción, Spinoza la explica con un ejemplo aparentemente sencillo: «Basta con acercarse a un escultor o a un carpintero y ellos mismos le [al crítico de esta distinción] mostrarán cómo conciben de determinada forma la estatua que todavía no existe y se la presentarán después ya existente» (PPC 239). Digo que el ejemplo es sólo aparentemente sencillo porque la clave no está en la distinción misma así ejemplificada sino en el contexto teológico que la envuelve. De hecho, el capítulo comienza hablando de Dios en tanto que contiene todas las esencias y de un modo más perfecto que en el mundo creado -la de la materia incluida, pace maniqueos-, contiene todas las ideas y es causa de todas las cosas. A quien se enfrenta Spinoza en este caso, por tanto, es a los escolásticos que aún recordaban las enseñanzas de Aristóteles. Como es sabido, para Aristóteles las esencias existen de suyo, son eternas, siempre en acto, en potencia sólo para los accidentes que van actualizando las perfecciones que las esencias poseen eternamente; $y$, como ideas, están en el pensamiento de aquellos sabios que las abstraen. Spinoza, sin embargo, piensa desde una metafísica creacionista hasta la médula: las esencias están comprendidas en los atributos de Dios, son creadas (cf. PPC, Prop. 12, Corolario 2..$^{\circ}$ ), y son eternas sólo en el sentido de que están contenidas en Dios; por eso es relevante la distinción entre aquella única esencia que implica la existencia -Dios- y el resto de esencias, una distinción ajena por completo a Aristóteles, donde la divinidad sustenta ontológicamente la naturaleza y la mueve pero no la crea. La existencia no está en cuestión en Aristóteles; para Spinoza, sin embargo, la existencia es la esencia «en cuanto se considera fuera de Dios y en sí misma, y se atribuye a las cosas después que fueron creadas por Dios» (PPC 238); de modo que, si las esencias fueran de suyo eternas, Dios sería irrelevante para ellas, no serían posibles sino necesarias y su ser no dependería de ser pensadas por Dios - posibilidades inconcebibles para Spinoza-. Como se ve, son dos metafísicas difícilmente conjugables.

El capítulo iII, por su parte, se dedica a la otra pieza clave de la división del capítulo I: la necesidad. Cosas cuya esencia sea necesaria sólo hay una, Dios, y cosas 
cuya esencia sea imposible todas las quimeras; aunque lo imposible, en tanto que negación, no es una afección ni un atributo del ser. Respecto a las cosas materiales, su esencia no implica su existencia, por tanto no pueden existir por sí mismas, sino por su causa, Dios, creador de todas las cosas. De ahí que «si está en el decreto divino que una cosa exista, existirá necesariamente; y si no, será imposible que exista» (PPC 240-1); o, en otra formulación: "Como nada se hace sin que lo haga el poder divino es fácil de ver que todo cuanto es hecho lo es por la fuerza del decreto y de la voluntad de Dios. Y como, además, en Dios no hay inconstancia ni cambio alguno (por Parte I, Prop. 18 y 20 Cor.) lo que él produce, debió decretar ab eterno producirlo» (PPC 243). De ahí que haya leyes eternas y un orden en la serie de las causas. Aquí los escolásticos a los que se enfrenta Spinoza son los que hablan de lo posible y de lo contingente como entidades intermedias entre lo necesario y lo imposible, es decir, aquellos que entienden que lo posible o lo contingente son afecciones del ser-Descartes incluido, pace Spinoza-. Spinoza parte de la definición de una cosa posible como aquella que tiene una causa eficiente conocida pero que no se sabe si va a ocurrir o no, y una cosa contingente como aquella cuya esencia ni es necesaria ni imposible, es decir, que puede ser real y cambiar. Pero, razona Spinoza, la posibilidad y la contingencia no son de las cosas; en ese caso, algo posible ni sería del todo ni no sería del todo, sería un intermedio imposible, y algo contingente sería aquello cuya esencia pudiera cambiar-digamos un triángulo que cambie sus propiedades-. Frente a ellos, Spinoza considera que, cuando se habla de posible o de contingente, no se habla de las cosas sino de la falta de conocimiento, es un defecto del entendimiento; si este comprendiera bien la esencia de las cosas y el orden de las causas, se vería que todo es necesario. Cuestión que le lleva al problema de cómo conciliar el libre albedrío y la predestinación divina, tema en el que Spinoza sigue puntualmente a su maestro: esa conciliación supera la capacidad humana.

Aclarados los puntos esenciales, Spinoza saca, implacable, las conclusiones. En primer lugar, el ser cuya esencia implica la existencia y es necesario es eterno, es decir, existe infinitamente; en los otros seres, creados, su existencia dura, es decir, perseveran en su ser; en ellos existencia y duración son sinónimos, si se elimina la existencia se elimina la duración y viceversa; cuando se compara la duración de algo con la duración de otra cosa se habla de tiempo, que, por tanto, no pertenece a las cosas sino que es un ens rationis. Lo mismo ocurre con otras nociones, como oposición, orden, conveniencia, diversidad, sujeto, adjunto; son entes de razón, no refieren a nada real fuera del pensamiento.

Estos matices preparan el asalto a la tesis escolástica principal que establece que las tres afecciones o atributos principales del ser son la unidad, la verdad y el bien. Spinoza pregunta qué ańaden al ser, es decir, si la diferencia entre ser y unidad, entre ser y verdad, o entre ser y bien remite a algo fuera del pensamiento que sea distinto del ser. Y responde que, si se considera el asunto sin prejuicios, hay que responder que no; de modo que la unidad, la verdad y el bien no cualifican el ser sino que son modos de pensar-de nuevo, habría que exclamar-, son términos que utilizamos para entender el ser, pero no forman parte de él. Los escolásticos «confunden los entes de razón con el ser real» (PPC 245). Con todo, Spinoza acepta la terminología habitual según la cual Dios es uno y único, aunque «sólo impropiamente decimos que Dios 
es uno y único ${ }^{19}$ (PPC 246). En cuanto a la verdad, Spinoza rastrea la genealogía del término y establece que surgió para distinguir las narraciones que contaban algo ocurrido realmente, llamadas verdaderas, de las que no, llamadas falsas; de ahí la tomaron los filósofos para su definición clásica de verdad como adecuación, pero las ideas, verdaderas o falsas, «no son más que narraciones o relatos de naturaleza mental» (idem.); sólo de forma metafórica se dice que las cosas mismas son verdaderas cuando, en sí mismas, simplemente son, ni verdaderas ni falsas. La verdad entonces equivale a certeza: cuando una idea es tan clara y distinta que elimina toda duda; tampoco es riguroso llamar a las cosas mismas inciertas o dudosas, salvo metafóricamente. Finalmente, respecto al bien, Spinoza establece que cualquier cosa en sí misma ni es buena ni es mala; es más, a veces, la misma cosa puede ser buena o mala en función de sus relaciones o incluso indiferente. De Dios sí se dice verdaderamente que es el sumo bien, dado que conserva a todas las cosas en su ser, pero no hay un mal absoluto - no hay demonios, como afirma en el Tratado breve, cap. 25-. La tesis criticada aquí es que hay un bien que todas las cosas persiguen -conatus-, por tanto es distinto el ser y el bien. De nuevo Spinoza considera que esa es una distinción de razón, que no refiere a cosas distintas en la realidad; en efecto, todas las cosas perseveran pero tal perseverancia no es distinta de cada cosa-como el movimiento no es distinto de la fuerza el movimiento-, de lo contrario el conatus necesitaría perseverar en su perseverancia, y así sin fin. La parte propiamente metafísica de las Cogitata acaba aplicando el mismo esquema a la perfección; esta es relativa, como el bien, aunque la esencia de Dios es perfección infinita ${ }^{20}$.

Desde el vocabulario spinoziano, se podría decir que, puesto que el ser se divide realmente sólo en sustancia y modo, la unidad, etc., para ser reales, tendrían que ser modos, es decir, señalables y cuantificables, lo que no es el caso; podrían ser entonces afecciones, es decir, atributos o características que fueran inseparables del ser realmente y sólo distinguibles con el pensamiento; pero resulta que son características añadidas por el pensamiento, cuando este compara o relaciona unas cosas con otras; respecto a Dios, como ser necesario, sin embargo, se pueden considerar características no del todo impropias, pero no rigurosas porque, por ejemplo: ¿en relación con qué se dice que Dios es sumamente perfecto si nada hay fuera de él que sirva de criterio?, y así en lo demás. De hecho, lo que hace Spinoza es eliminar las entidades metafísicas que poblaban el universo escolástico con realidades intermedias como las llamadas formas sustanciales o accidentes reales (PPC 249); para él, además de Dios, no existe nada más que o cosas particulares, extensas o mentales, o palabras; $y$, estas, propiamente, no existen.

${ }_{19}$ En rigor, es impropio decir que Dios, en tanto que ser infinito, sea separable de los demás seres -que sea uno -o que tenga una naturaleza de la que carezcan otros -que sea único-, dado que no hay nada fuera de él con lo que relacionar.

${ }^{20}$ Nótese que Spinoza está defendiendo que no hay personas buenas y malas ni mejores ni peores ni santas ni pecadoras, en sí mismas consideradas; además, Dios ayuda a todos por igual, independientemente de lo que hagan. 
En la Segunda Parte de las Cogitata, la propiamente teológica, se centra Spinoza en el ser de Dios, pero no en relación con las características que Descartes le atribuía, ya recogidas en la Parte Primera de PPC, sino tal como era presentado por otros teólogos del momento; de modo que es una ocasión magnífica para entender el contexto en el que tanto Descartes como Spinoza pensaron, y permite, además, comprobar las grandes diferencias entre el Dios de Spinoza y el Dios de los predicadores y teólogos de su época.

Algunos teólogos, por ejemplo, atribuían duración a Dios argumentando que desde que creó Adán hasta su siglo habría aumentado la duración de la existencia de Dios; pero esto, argumenta Spinoza, supondría separar en Dios su existencia y su esencia, y entender su existencia al modo de las cosas creadas, que duran y que son divisibles y cuya existencia actual no es la causa de su existencia futura; pero en Dios esencia y existencia se implican, luego Dios no dura, es eterno e infinito, no divisible. Según Spinoza el error se debe a la pobreza del lenguaje, que hace que, por ejemplo, se diga que el mundo fue creado ab eterno o que las esencias son eternas; pero hablando así se pierde lo fundamental: entender de qué modo tan distinto a las cosas Dios es eterno. La eternidad no es «un tipo de duración» (PPC 251), es «una existencia en acto infinita» (PPC 252); las cosas creadas, en todo caso, tienen una duración sin fin en ambos sentidos, pero no son eternas ${ }^{21}$.

Respecto a que Dios sea único, Spinoza no discute tanto el término como el tipo de argumentación, que él vincula a la implicación de existencia y esencia, pero que algunos teólogos argumentan de modo extrínseco así: si uno pudo crear el mundo, los demás sobran; si todo va dirigido a un fin, basta un solo autor.

Respecto a que Dios sea inmenso, Spinoza advierte que se suele confundir inmensidad e infinitud. Dios, propiamente, es infinito, entendido como «algo máximamente positivo", a pesar de que la palabra misma es negativa; por el contrario, se dice de él que es inmenso en relación con el mundo del que es causa, la inmensidad por tanto no es una característica absoluta. Además, la inmensidad tiene varios riesgos: 1) se asocia a la cantidad, impropia de Dios; 2) explica la omnipresencia de Dios como la de un espectador en el teatro; 3 ) a veces, se distingue entre inmensidad de esencia, de potencia y de presencia, cuando en Dios no se dan esas distinciones; incluso se dice que Dios es omnipresente no por su esencia sino por su poder, pero esto lo hacen porque «comparan su poder con el poder de los reyes» (PPC 255).

Respecto a que Dios sea inmutable, Spinoza lo relaciona con que sea incorpóreo, por lo que los cambios materiales no le afectan, y tampoco nada externo le hará cambiar ni cambiará por él mismo. El inconveniente aquí está en que las Escrituras hablan de Dios como airado o triste por los pecados humanos, lo que indicaría que algo externo le hace cambiar; Spinoza, obviando la importancia de esos pasajes para el creyente, argumenta que son formas metafóricas de hablar ${ }^{22}$.

21 Esta distinción no aparece en el Tratado breve.

22 En el Tratado breve, defiende que Dios, propiamente, no ama al ser humano (cf., cap. 24). 
Respecto a que Dios sea simplicísimo, Spinoza se apoya en las tres distinciones que había establecido Descartes y argu menta que en Dios no puede haber distinción real ni modal, de modo que sólo hay en él distinciones de razón, que, propiamente, no son distinciones; por tanto Dios es simple. Queda el campo libre completamente del «fárrago de distinciones de los Peripatéticos» (PPC 259).

Respecto a que Dios sea vida, Spinoza acude a las fuentes, nada menos que a los peripatéticos y al famoso pasaje de la Metafísica XII 1072, donde se dice que la vida de la divinidad es la actividad del pensamiento, en contraposición a la vida de las plantas, animales y humanos, que depende, respectivamente, del alma vegetativa, sensitiva e intelectiva ${ }^{23}$. Con todo, Spinoza propone definir vida como "la fuerza por la que las cosas perseveran en su ser» (PPC 260), que no es propia de las cosas, sino de Dios, el cual, propiamente, es vida. Ahora bien, la vida de Dios, para Spinoza, no se refiere sólo al entendimiento, sino también a la voluntad y al poder, por más que, en tanto que simple y perfecto, no se distingan realmente entre sí: Dios es omnisciente, omnipotente y creador. Su sabiduría excluye el entendimiento en potencia, llegar a conclusiones mediante el razonamiento y que sus ideas se refieran a objetos externos a él mismo.

Por eso Spinoza considera un error afirmar que hay una materia coeterna con Dios, autónoma y externa a él, a la que él habría dado forma; o defender que hay cosas posibles o contingentes en sí mismas, por lo que Dios tendría que conocerlas en base a la experiencia. Para Spinoza, por el contrario, «fuera de Dios no hay ningún objeto de su ciencia, sino que él mismo es el objeto de su ciencia, incluso su misma ciencia» (PPC 262). De modo que, aunque Dios tenga la idea de la naturaleza en su conjunto y decrete su creación, a su conocimiento de las cosas creadas no se le llama, propiamente, ciencia "porque si Dios hubiera querido, las cosas creadas tendrían una esencia distinta, lo cual no sucede con el conocimiento que Dios tiene de sí mismo" (PPC 263). La típica cuestión escolástica que surge aquí es si Dios conoce los males, el pecado y los entes de razón, cuestión a la que Spinoza responde, hábilmente, que los conoce como lo que son: nunca como características de las cosas mismas -en ese caso serían causadas por Dios mismo-, sino como apelativos que utiliza la mente humana. Y, esta vez sin nombrarlos, vuelve a discutir con los peripatéticos, acaso averroístas, a los cuales les parecía impropio de la divinidad que conociera los particulares, por eso defendían que Dios sólo conoce los universales, los ángeles, los incorruptibles cielos, las ingeneradas especies, etc. Spinoza, nominalista, pregunta: "¿Qué hay más absurdo que separar el conocimiento divino de las cosas singulares, que no pueden existir ni un solo instante sin el concurso de Dios?» (PPC 263); es

${ }^{23} \mathrm{Ha}$ de notarse que Spinoza utiliza aquí el término anima cuando se refiere a las tres almas aristotélicas y mens para referirse a la mente de Dios, cuya vida consiste en la actividad del pensamiento. Como Atilano Domínguez traduce siempre por alma se pierde ese matiz, tan importante para Spinoza, que aquí afirma, muy cartesianamente: «Por lo que respecta a aquellas tres almas que atribuyen a las plantas, los brutos y los hombres, ya hemos demostrado suficientemente que no son más que ficciones, cuando mostramos que en la materia no hay más que operaciones y entramados mecánicos» (PPC 259). 
más, Dios conoce las cosas singulares, que son las existentes realmente; los universales los conoce sólo en la mente humana, único lugar donde están.

Obviando el dogma de la Trinidad, del que afirma que «no podemos formarnos un concepto claro y distinto, pese a que creemos firmemente que, en la beatísima visión de Dios prometida a los fieles, Dios se lo revelará a los suyos» ${ }^{24}$ (PPC 264), Spinoza, respecto a la voluntad de Dios, repite que las Escrituras hablan metafóricamente cuando atribuyen odio, irritación o amor a Dios. En este contexto se encuentra uno de sus textos de antología:

La verdad no es incompatible con la verdad ni puede la Escritura enseñar las simplezas que el vulgo imagina. Pues, si en ella halláramos algo contrario a la luz natural podríamos rechazarlo con la misma libertad con que rechazamos el Corán o el Talmud. Pero no se permita pensar que se pueda encontrar en las Sagradas Escrituras algo que sea incompatible con la luz natural (PPC 265).

En relación con la omnipotencia de Dios, Spinoza aborda tres cuestiones espinosas: 1) si hay cosas que, de suyo, sean imposibles, como un cuadrado redondo, y otras de suyo necesarias, como las propiedades del triángulo, y otras simplemente posibles; si así fuera, Dios sería omnipotente sólo respecto a las posibles; como se puede adivinar, Spinoza responde que todas las cosas son igualmente necesarias, esas distinciones no están en las cosas mismas sino en la mente de quienes las hacen, que muestran ser ignorantes; 2) si Dios hubiera hecho las cosas distintas a como son ahora, si lo verdadero seguiría siendo verdadero o se convertiría en falso; a lo que Spinoza responde que, en ese caso y dado que Dios no es engañador, habría dado a los humanos el entendimiento ajustado a esa distinta naturaleza de las cosas, de modo que podríamos conocerla; 3) si los milagros suponen que Dios hace algo fuera de las leyes de la naturaleza; la previsible respuesta spinoziana es, de nuevo, de antología:

Mayor milagro puede considerarse que Dios gobernase siempre el mundo según el mismo orden, fijo e inmutable, que si abrogase, por la necedad humana, las leyes que él mismo sancionó en la naturaleza del mejor modo y por simple libertad (algo que solo puede ser negado por quien esté del todo obcecado) (PPC 267) 25.

${ }^{24}$ Spinoza se incluye dentro de los cristianos; además, cita con aprobación a san Pablo en PPC 264-5 y su afirmación de la relación de Dios con el hijo de Dios es ortodoxa: «El hijo de Dios no es creado sino que, como el padre, es eterno. En efecto, cuando decimos que el padre engendró al hijo desde la eternidad no queremos decir sino que el padre ha comunicado siempre al hijo su eternidad" (PPC 271). Ahora bien, Spinoza defiende que Dios es simplicísimo y que, en Él, no cabe distinguir propiamente entre entendimiento, voluntad y poder, que era uno de los modos tradicionales de explicar la Trinidad; de hecho, del tecnicismo creado ad hoc para el dogma de la Trinidad, persona o personalitas, dice Spinoza que no lo entiende (cf. PPC 264); de modo que su visión de Dios se acercaría al más monoteísmo judío o musulmán que al difícil monoteísmo cristiano.

${ }_{25}$ En el capítulo final, vuelve Spinoza sobre el tema de los milagros. Ahí acepta, «con la mayoría de los teólogos más prudentes» (PPC 276-7), que los milagros se pueden explicar por leyes naturales desconocidas por los humanos. 
Respecto a la creación, Spinoza quiere matizar varias afirmaciones con las que no está de acuerdo: 1) no le gusta la expresión creación ex nibilo, dado que, puesto que no puede significar creación a partir del no ser absoluto, parece indicar que se crea a partir de la nada, como si la nada fuera algo material; 2) la creación no fue hecha con vistas a un fin, que sería externo a Dios, algo imposible; 3) la creación lo es de la sustancia, no hay creación separada de los accidentes ni de los modos, ya que estos están presupuestos en aquella; 4) la duración comienza con las cosas creadas y acaba con ellas; el tiempo presupone el pensamiento humano; sólo Dios, no el mundo, es, propiamente, eterno; 5) Dios, propiamente, no conserva las cosas sino que las crea constantemente, dado que el momento presente no está vinculado con el siguiente.

Spinoza rechaza incluso la clasificación tradicional de los atributos divinos en comunicables e incomunicables, dado que le parece que proyecta sobre Dios características humanas, y propone la suya propia ${ }^{26}$ : atributos que explican su esencia en cuanto acción, como la inteligencia, la voluntad, la vida y la omnisciencia, y atributos que exponen su modo de existir, como la unidad, la eternidad y la necesidad. La sustancia creada la divide Spinoza, en el último capítulo ${ }^{27}$ de sus Cogitata, siguiendo a Descartes ${ }^{28}$, en extensa, la materia corpórea, y pensante, la mente humana -de los ángeles no habla, dado que no se conocen por luz natural-. Las mentes humanas son creadas por Dios aunque no se sabe cuándo. Desde luego, dado que tiene una concepción no corporalista de la mente, rechaza la explicación que seguramente se remonta a Tertuliano según la cual el alma pasa de padres a hijos como el esqueje de la vid que vuelve a brotar una vez plantado de nuevo; Spinoza razona que esa generación correspondería, en todo caso, al modo, no a la sustancia, que no admite generación. En este sentido, la sustancia es inmortal -no en sentido absoluto, puesto que es creada-; así, el cuerpo se destruye pero la sustancia extensa no. Del mismo modo, la mente humana, en tanto que sustancia es inmortal ${ }^{29}$. Recuérdese que

${ }^{26}$ Este es el asunto que le preocupa a Spinoza especialmente y al que le dedicó la Primera Parte de su Tratado breve.

${ }^{27}$ Es de reseñar que en este capítulo aparece varias veces la palabra anima alternando con mens sin ningún matiz semántico apreciable. Cf. infra citas PPC 276 y PPC 279. Indicio acaso de una redacción primeriza.

${ }_{28}$ Aunque, en el Tratado breve-«Diálogo entre el Entendimiento, el Amor, la Razón, y la Concupiscencia»-, la distinción cartesiana de tres sustancias es puesta en boca de la Concupiscencia y criticada.

${ }^{29}$ Spinoza abre una cuestión sobre la que Descartes pasó de puntillas: si la res cogitans se refiere al ámbito de lo mental, como la res extensa se refiere al ámbito de la materia, o si la mente de cada persona es una sustancia pensante, de modo que habría miles de sustancias. Spinoza habla tanto en singular como en plural y, como aborda la cuestión de cuándo se crea la mente, se entiende que se refiere a la de cada persona. Que el matiz es importante se comprueba cuando se compara la situación con la res extensa; en tanto que sustancia es inmortal, aunque cada cuerpo individual se destruye, por lo que es mortal. Habría que decir, entonces, para hablar con propiedad, que la sustancia creada se divide en extensión y en múltiples mentes. $\mathrm{O}$ bien, que la mente de cada persona, en tanto que mero conjunto de ideas, sufre la misma suerte que su cuerpo, y que es el ámbito de lo mental el que es inmortal. Esta cuestión parece aludida por Meyer en PPC 132 y es abordada por Spinoza en el Tratado breve, cap. 23. 
Descartes no demostró exactamente que el alma fuera inmortal sino que era separable del cuerpo, y dejaba a la fe la confianza en que el poder de Dios las separaría efectivamente ${ }^{30}$. Spinoza, sin embargo, resuelve la cuestión así:

De las leyes de la naturaleza se sigue claramente que el alma es inmortal. Ahora bien, las leyes de esa naturaleza son los decretos de Dios, revelados por la luz natural, como consta también con toda evidencia por lo que precede, y hemos demostrado, además, que esos decretos son inmutables. De modo que concluimos, pues, que Dios ha manifestado a los hombres su voluntad inmutable sobre la duración de las almas, no sólo por la revelación, sino también por la luz natural (PPC 276).

Con todo, la cuestión principal, que sirve de colofón a la obra y a la que Meyer dirige la atención del lector desde el final de su presentación (cf. PPC 132), es la libertad de la voluntad. Aquí la situación de Spinoza es difícil porque, frente a los planteamientos escolásticos, defiende los de su maestro, aunque tiene los suyos propios, que ya conocían sus amigos por el Tratado breve. Curiosamente la tesis escolástica criticada y la propia de Spinoza coinciden en que la voluntad no es libre -aunque la coincidencia se desvanece cuando se entiende el distinto significado de los términos-; mientras que la defendida aquí, con Descartes, es que la voluntad sí es libre. Se da la circunstancia de que Spinoza cita al autor criticado al que tiene de referencia, con lo que ha dado visibilidad a uno de los profesores que intentaban renovar la escolástica europea teniendo en cuenta las obras de Descartes o Bacon. Se trata de Adriaan Heereboord (1613-1661), profesor de la Universidad de Leiden, autor por cierto de una obra donde compara la filosofía natural de Aristóteles y la de Descartes. La obra aludida por Spinoza es Meletemata philosophica, un compendio donde se abordan cuestiones metafísicas, éticas, físicas según teoremas, lógicas, de filosofía natural y de pneumática. En ella, Heereboord defendía que la voluntad, al ser indiferente en sí misma, es indeterminada; toda decisión que tome dependerá de causas externas a ella, que la determinarán a obrar; de ahí que la voluntad no es libre. Spinoza responde que la voluntad sí es libre, y se remite a la Meditación Cuarta de las Meditaciones cartesianas y a Principia I, art. 39.

Lo curioso es que los argumentos spinozianos son cartesianos sólo en la mitad: cuando critica a Heereboord que considere la voluntad como si fuera un cuerpo, obviando la diferencia cartesiana entre extensión y pensamiento; sólo desde esa confusión, argumenta Spinoza, se puede entender la voluntad como una tabla rasa, como un cuerpo sometido a dos fuerzas equivalentes que lo mantendrían en un indeciso equilibrio constante o como algo así como la materia prima de Aristóteles; la voluntad, sin embargo, es mental, decide si afirmar o negar, si dudar o no, y nadie deja de tener esa conciencia de libertad, incluso cuando es coaccionado desde el exterior. Lo interesante, con todo, es la otra parte de la argumentación spinoziana:

30 Descartes acude a la divinidad para que, una vez distinguidos el cuerpo del alma, «puedan darse separadamente, al menos gracias a Dios» (M 78); y en las respuestas a las sextas objeciones, reconoce explícitamente que «sólo la fe puede saber que el alma humana suba a lo alto» (M 431). 
que la voluntad no es una facultad distinta del pensamiento; en realidad la voluntad no es algo, sino el conjunto de voliciones, que son actos de pensamiento - actiones cogitativae - indistinguibles del resto, dado que todo acto de pensamiento es una afirmación o una negación. Estas son sus palabras: «La voluntad no es nada aparte de la mente misma, a la que llamamos sustancia pensante, esto es, que afirma y que niega» (PPC 279). De ahí se seguiría que no hay distinción entre voluntad y entendimiento, por lo que aquella no puede ser mayor que este, como argumentaba Descartes; y el libre albedrío, que Descartes consideraba la huella divina en el hombre que de algún modo lo hacía semejante a Dios, quedará disuelta por Spinoza en la Etica, al entender que cada acto de pensamiento -el acto de sentirse libre incluido, se entiende- es tan necesario como cada suceso extenso; todo está preordenado en los eternos decretos de Dios, único origen de toda determinación. La objeción a esta tesis, según la cual no se podría condenar al asesino ni al pecador, dado que actuarían de forma necesaria, sí la tiene prevista Spinoza: «Si sólo hubieran de ser castigados aquellos que imaginamos que sólo pecan por su libertad, ¿̨por qué se ven los hombres forzados a exterminar las serpientes venenosas? Pues sólo pecan por su propia naturaleza, sin que puedan obrar de otro modo» (PPC 265).

\section{CONCLUSIÓN Y PERSPECTIVAS}

De lo anterior, se puede concluir que Spinoza, sin duda, era cartesiano, dado que gran parte de sus cuestiones y vocabulario proceden de una atenta lectura de los Principia y de las Meditationes. Sin embargo, creo que llevaban razón los cartesianos que rechazan incluirlo en su grupo. Como se ha comprobado en este estudio, Spinoza obvia el sistema del mundo completo que Descartes defendió y por el que era reconocido: nada de anatomía, de cosmología, de geometría, de geología, de meteorología, de hidrología, de metalurgia, de química; y mucho de metafísica y de teología. En un momento, además, en que los cartesianos afrontaban fuertes, variadas y consistentes críticas al sistema científico de su maestro. Spinoza, sin embargo, en una actitud que me recuerda vivamente la de Miguel Servet, tiene la virtud de centrarse en lo más incómodo y de molestar a todos, enemigos y supuestos amigos. El mismo Descartes había tenido que abandonar Holanda, el país entonces más libre de Europa, acusado por católicos y por calvinistas desde su flanco teológico. Y precisamente ese flanco es el que interesa a Spinoza. Su amigo y prologuista, Luis Meyer, lo anuncia con claridad: «Los fundamentos de las ciencias descubiertos por Descartes, y lo que ha edificado sobre ellos, no bastan para explicar y resolver todas las dificilísimas cuestiones que surgen en la metafísica, sino que se requieren otros, si deseamos levantar nuestro entendimiento a aquella cumbre del conocimiento" (PPC 132-3). Del cogito como fundamento hay que pasar, por tanto, a Dios como fundamento.

La diferencia de talante se puede sintetizar diciendo que Descartes fue un científico mientras que Spinoza fue un reformador. Sin olvidar que allí donde Descartes se mostraba prudente y conciliador, Spinoza defendía implacable las consecuencias de sus principios. La ironía de la historia se muestra en que las explicaciones 
anatómicas, físicas y cosmológicas que a Descartes le parecieron claras y distintas han resultado tener explicaciones alternativas, de modo que la claridad y la distinción no son criterios de verdad definitivos, por más que Descartes los fundamentara en Dios mismo. En el caso de Spinoza, sin embargo, sus ideas sobre la felicidad o sobre la sociedad justa siguen siendo válidas, pero al lado de otras distintas; la apelación a Dios, en este caso, tan importante para Spinoza, tampoco fue definitiva para que fueran universalmente admitidas. Sería por eso interesante poner frente a frente Las pasiones del alma de Descartes, por un lado, y la Parte Segunda del Tratado breve y la Parte Tercera de la Ética, por el otro. Se comprobaría de qué modo las discrepancias teológicas entre maestro y seguidor aparecen también en la antropología.

Respecto a la debatida cuestión del ateísmo de Spinoza, es difícil, tras leer su libro, acusarlo sin más de ateo, porque pocas palabras aparecen en él más que la palabra Dios. Sin embargo, en su época no bastaba con apelar a Dios para quedar libre de culpa. Y lo cierto es que el Dios de Spinoza se aleja tanto del Dios bíblico -que se manifiesta corpóreamente, que hace milagros, que interviene en los sucesos humanos como un actor más, que premia, castiga, ama, se enfurece, etc.- como de la divinidad aristotélica -sin creación ni recreación constante, sin decretos, sin desvitalizar la naturaleza-. De ahí que Spinoza navegue entre dos aguas y que pueda recibir críticas por ambos lados. Desde luego, creo que respecto al Dios de los predicadores y de los teólogos dogmáticos, Spinoza es ateo; desde ahí, por cierto, le llegaron las críticas y prohibiciones en su época -y seguramente su expulsión de la comunidad judía-, y no sin razón porque en el Dios spinoziano no reconocerían el propio. Sin embargo, considero que ese desfase se debe, precisamente, a que Spinoza se centró en el aspecto más propiamente religioso de la idea de Dios y a que eliminó casi en su totalidad la tradicional proyección humana sobre él. El Dios de Spinoza es necesidad sin rostro humano, en él la voluntad, el entendimiento, el poder y la vida se identifican; poco queda en él de humano, salvo que es creador y que la creación sigue sus decretos y a él le debe su necesidad. Desde este punto de vista, se puede decir que Spinoza no sólo no es ateo sino que es sumamente teísta, tanto que somete a Dios todo lo natural y todo lo humano, incluyendo el centro humano de decisión, que desaparece como tal. Ser ateo, en sentido spinoziano, sería afirmar que el ser cuya esencia implica una existencia necesaria e infinita positivamente, cuyos decretos atraviesan la creación en forma de leyes naturales inmutables que determinan la esencia y la existencia singular de todas las cosas, corporales y mentales, es un ens rationis. $\mathrm{O}$, en otra formulación, que la naturaleza existe de suyo, con regularidades que los humanos entendemos como leyes naturales, las cuales, por ello, van siendo modificadas conforme cambia el conocimiento humano de la naturaleza. Y ninguna de las dos formulaciones sería aceptada por Spinoza.

RECIBIDO: noviembre de 2017, ACEPTADO: marzo de 2018 